\title{
A Retrospective Study of Maternal and Fetal Outcome in Severe Oligohydromnios.
}

\author{
Dr. Sanjay kumar $C^{1}$, Dr. Lalitha shivanna ${ }^{2}$, Dr. Pradeep $\mathrm{MR}^{3}$, Dr. Deepthi HR ${ }^{4}$ \\ ${ }^{1}$ Assistant Professor, Dept of OBG, Mandya Institute Of Medical Sciences , Mandya-571401 \\ ${ }^{2}$ Professor, , Dept of OBG, Mandya Institute Of Medical Sciences, Mandya-571401 \\ ${ }^{3}$ Assistant Professor, Dept of OBG, Mandya Institute Of Medical Sciences , Mandya - 571401 \\ ${ }^{4} J u n i o r$ Resident, Dept of OBG, Mandya Institute Of Medical Sciences , Mandya - 571401
}

\begin{abstract}
Amniotic fluid is the nourishing \& protecting liquid of the amnion of a pregnant woman\& at 10 weeks it contains proteins, carbohydrates, lipids, phospholipids, urea, electrolytes all of which helps in the growth of fetus \& in later stages it consists of fetal urine. As the fetus grows amniotic fluid increases to maximum of $800-1000 \mathrm{ml}$ at 34 weeks and decreases to $600-800 \mathrm{ml}$ at 40 weeks. It protects the baby by cushioning too. Any decrease in the amniotic fluid leads to intra uterine growth restriction, meconium aspiration syndrome, severe birth asphyxia, low Apgar scores, congenital abnormalities, contracture of the limbs, clubbing of feet \& hypoplastic lungs. so early detection and intervention might decrease the perinatal mortality and morbidity and decrease in the C-section rate also. Aims \& Objectives: To study the effect of severe oligohydramnios on maternal morbidity, neonatal morbidity \& mortality \& incidence of congenital abnormalities. Materials \& Methods: 100 cases of term pregnancies with severe Oligohydromnios admitted to labour room, between June 2013 to Dec 2013 were selected. After considering inclusions \& exclusion criteria, a detailed history was taken and general physical examination, obstetric examination\& clinical pelvimetry was done \& Bishops score was assessed. Severe Oligohydromnios was confirmed by estimation of AFI by USG \& in all cases Doppler study was done. Conclusion: Severe Oligohydromnios has been linked with adverse perinatal outcome which includes structural anomalies, SGA, IUGR, post maturity syndrome, cord compression, MAS \&FHR variations \& increased perinatal morbidity \& mortality. Hence it demands early diagnosis, intense antenatal care of maternal \& fetal factors, intervention with hydration and isotonic therapy, intense intrapartum care, intervention at the appropriate time to decrease fetal morbidity \& mortality.
\end{abstract}

Key words: Oligohydromnios, Maternal outcome, Fetal outcome, Caesarean section, Induced labour

\section{Introduction}

Oligohydromnios by definition is (1) Amniotic fluid volume $<5^{\text {th }}$ percentile for gestational age ${ }^{1}(2)$ AFI $<5^{2}$ (3) Single vertical pocket $<2 \mathrm{~cm}$. Incidence is $0.5-5 \%$ of normal pregnancies ${ }^{3}$. It cushions the baby and acts as shock absorber, protects cord compression, helps in the development of musculoskeletal systems, GIT and pulmonary development and prevents adhesions. It maintains fetal body temperature, supplies nutrition and has bacteriostatic properties. Decrease ${ }^{4}$ in amniotic fluid has been correlated with increase in riskof IUGR, pulmonary hypoplasia ${ }^{5}$, MAS, fetal heart conduction abnormalities, IUFD and increase in the rate of induction of labour \& C-section ${ }^{6}$. In 1987 Phelan et $\mathrm{al}^{7}$ introduced AFI to assess the amount of amniotic fluid in the amniotic $\operatorname{sac}^{6}$ using 4 quadrant technique. AFI is a poor predictor of perinatal outcome. A low AFI might warrant increase in the obstetric intervention without improving the neonatal or maternal outcomes ${ }^{1,7,8}$. So individualised care with consideration of maternal and fetal factors, cervical readiness and emotional readiness for labour should be considered.

\section{Materials \& Methods:}

This retrospective study was conducted in the department of OBG, MIMS Mandya from June 2013Dec 2013. The study group comprised of 100 patients, who were admitted to Labour room with diagnosis of severe Oligohydromnios both clinically \& by USG. .Inclusion criteria: 1. Singleton pregnancy 2. Intact membranes 3. AFI 0-3 by USG. Exclusion criteria: 1. Abnormal position \& presentation 2. Associated with renovascular disorders 3.Polyhydromnios 4.PROM 5.fetal anomalies 6. Multiple pregnancies.

A detailed history was taken, general physical \& systemic examination, obstetric \& pelvic examination was done and Bishop's score was assessed. All required investigations were done including UGS for AFI and Doppler study. Effect of Oligohydromnios on Pregnancy outcome \& fetal outcome was observed with respect to (1) induction of labour and mode of delivery, (2) incidence of meconium stained liquor, (3) intrapartum fetal distress, (4) neonatal morbidity \& mortality by Apgar score and NICU admission.

Decision for delivery either by induction or emergency LSCS was taken depending upon Bishop's score $\&$ as required and later cases were reviewed for maternal and perinatal outcome. 


\section{Results:}

$90 \%$ of the cases were unbooked and $70 \%$ belonged to age group of $24-30 \mathrm{yrs}$. Incidence of Oligohydromnios was $60 \%$ in primi and $40 \%$ in multi. Bishop's score was $<4$ in $90 \%$ of cases \& $>6$ in $10 \%$ of cases. AFI was 0 in $90 \%$ of the cases and 2-3 in $10 \%$ of the cases. Abnormal Doppler was present in $25 \%$ of the cases. Associated high risk factors were idiopathic in $55 \%$ of cases, PIH in $10 \%$ cases.,Anaemia in $25 \%$ of the cases \& IUGR in $10 \%$ of cases. Operative delivery was higher in AFI 0 with abnormal Doppler group \& $10 \%$ had NICU admissions.

In our study $10 \%$ of cases with Bishop's score more than 6 had induction of labour with cerviprime gel and later accelerated by ARM and oxytocin drip delivered vaginally. 2 babies died due to meconium aspiration syndrome after NICU admission. In $70 \%$ of the cases there was no liquor at all, scanty clear liquor seen in $15 \%$ of the cases and thick meconium stained liquor in another $15 \%$ of the cases.

Table I: Relation between Bishop's score,AFI and pregnancy outcome.

\begin{tabular}{|l|l|l|l|}
\hline AFI & $\%$ & Vaginal delivery & C-section \\
\hline 0 & 90 & $3(3.3 \%)$ & $87(96.6 \%)$ \\
\hline $2-3$ & 10 & 10 & - \\
\hline
\end{tabular}

Table II: Associated High risk factors\& outcome of labour.

\begin{tabular}{|l|l|l|l|}
\hline $\begin{array}{l}\text { Category 1 } \\
\text { (High Risk) }\end{array}$ & Normal vaginal delivery & C-section & Total \\
\hline PIH 10 & - & 10 & 10 \\
\hline Anaemia 25 & $8(32 \%)$ & $17(68 \%)$ & 25 \\
\hline Severe IUGR 10 & - & 10 & 10 \\
\hline Idiopathic 55 & $5(9.1 \%)$ & $50(90.9 \%)$ & 55 \\
\hline
\end{tabular}

Table III: Fetal outcome

\begin{tabular}{|l|l|}
\hline Growth retardation & $20 \%$ \\
\hline Apgar score $<7$ in1-5mins & $15 \%$ \\
\hline NICU Admission & $10 \%$ \\
\hline Neonatal death & $2(2 \%)$ \\
\hline
\end{tabular}

\section{Discussion:}

Oligohydromnios is associated with increase risk of IUGR, pulmonary hypoplasia, MAS, fetal heart abnormalities \& increase in C-section. IUGR is a significant in utero complication that can have profound effects on brain development including reduced myelination \& deficit can continue into adulthood. In our study the mean age group is between 24-30yrs, it correlates with the study of Casey et $\mathrm{al}^{5}$.

Incidence of severe Oligohydromnios was $60 \%$ in primigravida \& it correlates with the study of Donald $\mathrm{D}$ et $\mathrm{al}^{6}$. In patients with AFI $0,3.3 \%$ had vaginal delivery \& the incidence of operative deliveries (96.6\%) was higher which does not correlate with studies by Weiss et $\mathrm{al}^{9}$ and others. In our study $25 \%$ had abnormal Doppler \& correlates with Weiss et al study ${ }^{9}$. Common indication for LSCS was fetal distress. In our study $20 \%$ of the babies were SGA \& $80 \%$ AGA, which is nearly comparable to the study by Brain M Casey et al where there was $24 \%$ SGA \& $75.5 \% \mathrm{AGA}^{5}$ and study by Manning et $\mathrm{al}^{10}$ incidence of AGA was $36 \%$. Mean birth weight was $2.4 \mathrm{~kg}$ which is similar to study by William ott et a ${ }^{11}$. In our study there was 2 neonatal deaths $(2 \%)$, where as study by Golan et al ${ }^{(12)}$, it was $6.3 \%$. In $70 \%$ of the cases there was no liquor at all, scanty clear liquor was seen in $15 \%$ of the cases \& thick meconium liquor in $15 \%$ of cases.

\section{Conclusion:}

Oligohydromnios is a condition where there is very low or absent amniotic fluid \& was first described by Potter. It demands intense Antepartum, Intrapartum care \& fetal surveillance, as it is frequently associated with IUGR, Fetal distress, PIH, PROM, Fetal renal abnormalities as renal agenesis, bilateral cystic kidneys and obstructive uropathy. It can occur in future pregnancy due to genetic abnormality. In our study maximum cases belonged to idiopathic Oligohydromnios and had poor bishop's score $(<4)$.

\section{Bibliography}

[1]. OLT WJ Revaluation of the relationship between amniotic fluid volume \& perinatal outcome. AMJ Ob Gynec:2004:192:18031809.

[2]. AmJCOG Antepartum fetal surveillance Washington D.C Practice Bulletin No.9

[3]. Leevan 1, Almond D, isolated oligohydromnios at term: is induction indicated ? J fampract 2005;54:25-32.

[4]. Phelan J P, Smith C V, Broussard P, Small M, amniotic fluid volume assessment using four-quadrant technique in pregnancy at 3642weeksof gestation(Reprod, med 1987;32(1)540-2) 

$\mathrm{BM}$, MC intire

Bloom SL,Lucas MJ, Santos R,Twickler DM et al. Pregnancy outcomes after antepartum diagnosis of oligohydromnios at or beyond 34weeks of gestation.AMJ Obstetrics \& Gynaecology 2000;182(4) 909-12.

[6]. Leeman L, Almond D, Isolated oligohydromnios at term; is induction indicated?Jfampract 2005;54:25-32.

[7]. Moses J, Doherty D, MagannE,ChauhanS,Morrison J. A randomized clinical trial of the intrapartum assessment of amniotic fluid index versus single deepest pocket technique. AmJOBS\&GYN 2004;190:1564-1570

[8]. Chauhan S, Sanderson M, Hendrix N,Magann E, Devoe L, perinatal outcome \& amniotic fluid index in the antepartum and intrapartum periods; A meta-analysis. AMJ obstetrics \& gynaecology 1999;181:1473-1478.

[9]. Hitschold T, Weiss E, Berle P, Muntefering H, Correlations of placental retarded maturation, fetaloutcome,Dopplersonographic findings in umbilical artery.

[10]. Manning FA, Hill LM, Platt LD, quantitative amniotic fluid volume determination by USG; antepartum detection of IUGR, AmJObstetrics \&Gynecology 1981;139(3):254.58

[11]. OTT WJ , re-evaluation of relationship between amniotic fluid volume \& perinatal outcome. AmJ Obstetrics \& Gynaecology 2005;192(6);1803-9

[12]. Golan A, Lin G,EvronS,Aeirli S, Nio D, David MP, oligohydromnios, Maternal complication and fetal outcome in 145 cases. Gynecology\& obstetrics investigations 1994:37(2):91-5. 